\title{
Zika virus infection complicated by Guillain-Barré syndrome - case report, French Polynesia, December 2013
}

E Oehler (erwan.oehler@cht.pf) ${ }^{1}$, L Watrin ${ }^{2}$, P Larre ${ }^{2}$, I Leparc-Goffart ${ }^{3}$, S Lastère ${ }^{4}$, F Valour ${ }^{1}$, L Baudouin ${ }^{5}$, H P Mallet ${ }^{6}$, D Musso F Ghawche ${ }^{2}$

1. Internal medicine department, French Polynesia Hospital Center, Pirae, Tahiti, French Polynesia

2. Neurology department, French Polynesia Hospital Center, Pirae, Tahiti, French Polynesia

3. Institut de Recherche Biomédicale des Armées, National Reference Laboratory for arboviruses, Marseille, France

4. Laboratory of virology, French Polynesia Hospital Center, Pirae, Tahiti, French Polynesia

5. Intensive care unit, French Polynesia Hospital Center, Pirae, Tahiti, French Polynesia

6. Bureau de veille sanitaire - Direction de la Santé, Papeete, Tahiti, French Polynesia

7. Louis Mallardé Institute, Papeete, Tahiti, French Polynesia

Zika fever, considered as an emerging disease of arboviral origin, because of its expanding geographic area, is known as a benign infection usually presenting as an influenza-like illness with cutaneous rash. So far, Zika virus infection has never led to hospitalisation. We describe the first case of Guillain-Barré syndrome (GBS) occurring immediately after a Zika virus infection, during the current Zika and type 1 and 3 dengue fever co-epidemics in French Polynesia.

We report on a French Polynesian patient presenting a Zika virus (ZIKA) infection complicated by GuillainBarré syndrome (GBS).

\section{Clinical description}

In November 2013, a Polynesian woman in her early 405 , with no past medical history with the exception of acute articular rheumatism, was hospitalised in our institution for neurological deficits. She had been evaluated one day before (Day o: onset of neurological disorders) at the emergency department for paraesthesia of the four limb extremities and discharged. At Day 1 , she was admitted to the department of neurology through the emergency department because paraesthesia had evolved into ascendant muscular weakness suggestive of GBS. At Day 3, she developed a tetraparesis predominant in the lower limbs, with paraesthesia of the extremities, diffuse myalgia, and a bilateral but asymmetric peripheral facial palsy. Deep tendon reflexes were abolished. There was no respiratory nor deglutition disorders. The patient developed chest pain related to a sustained ventricular tachycardia, and orthostatic hypotension, both suggestive of dysautonomia. The echocardiography was normal, without signs of pericarditis or myocarditis. The electromyogram confirmed a diffuse demyelinating disorder, with elevated distal motor latency, elongated F-wave, conduction block and acute denervation, without axonal abnormalities. The administration of intravenous polyvalent immunoglobulin $(0.4 \mathrm{~g} / \mathrm{kg} /$ day for 5 days) allowed a favourable evolution, with no respiratory impairment necessitating tracheotomy or intensive care unit monitoring, and the patient was discharged home at Day 13. Paraparesis persisted after the end of hospitalisation, that imposed the use of a walking frame, and the facial palsy slowly disappeared. At Day 40 , she was able to walk without help and had a satisfying muscular strength score of 85/100.

Retrospectively, anamnestic data revealed that she had suffered from an influenza-like syndrome at Day - 7 , with myalgia, febricula, cutaneous rash, and conjunctivitis. Because an epidemic of Zika fever, which is still ongoing [1], had begun a few weeks prior to the patient presenting this syndrome, Zika fever was suspected.

\section{Laboratory analysis}

Laboratory findings showed no inflammatory syndrome and the blood count was normal. A twofold increase in transaminase level was observed. The analysis of cerebrospinal fluid (CSF) disclosed an albuminocytological dissociation with $1.66 \mathrm{~g} / \mathrm{L}$ proteins (norm: $0.28-0.52$ ) and 7 white cells $/ \mathrm{mL}$ (norm<10). Glycorrhachia was normal at $0.60 \mathrm{~g} / \mathrm{L}$. Usual aetiologies of GBS were eliminated: serological tests for human immunodeficiency virus (HIV), hepatitis B and C, Campylobacter jejuni and Leptospira were negative; and serological tests for cytomegalovirus, Epstein-Barr virus, and herpes simplex virus type 1 and 2 concluded to resolute infections.

Direct detection of dengue virus (DENV) by non-structural protein 1 (NS1) antigen (SD Bioline Dengue NS1 Ag 
ELISA, ALERE Australia) and reverse transcription-polymerase chain reaction (RT-PCR) [2], and ZIKA by RT-PCR [3], were negative on blood samples eight days after the beginning of influenza-like symptoms (corresponding to Day 1), prior to the administration of intravenous immunoglobulin. Blood samples taken at eight and 28 days after the beginning of the influenza-like syndrome were both positive for ZIKA-specific IgM and ZIKA- and DENV-specific IgG, assessed by in-house enzymelinked immunosorbent assays (in-house IgM antibody capture (MAC)- enzyme-linked immunosorbent assay (ELISA) and indirect IgG ELISA using inactivated antigen). On the last serum specimen sampled 28 days after the onset of influenza like syndrome, antibody specificity was determined by plaque reduction neutralisation test (PRNT) against serotype 1 to 4 DENV (DENV1-4) and ZIKA. A 90\% neutralisation titre $>1 / 320$ for DENV $1,1 / 80$ for DENV $2,>1 / 320$ for $\operatorname{DENV}_{3}, 1 / 20$ for

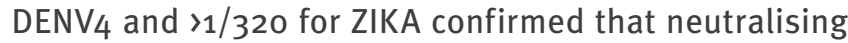
antibodies against ZIKA and the four DENV serotypes were present in the sera of the patient. These serological analyses indicated a recent infection by ZIKA, and argued for resolute infections by $\mathrm{DENV}_{1-4}$.

\section{Background on Zika virus infections}

Discovered in 1947 in the Zika forest in Uganda, ZIKA is an arbovirus of the flavivirus genus belonging to the flaviviridae family, as dengue, yellow fever, Japanese encephalitis, West Nile, and Saint-Louis encephalitis viruses. First human cases of ZIKA infection were described in the 1960s, first in Africa, then in southeast Asia [4-6]. Until 2007 when a large epidemic was described in Yap (Micronesia) [7], ZIKA infections remained limited to sporadic cases or small-scale epidemics. During the epidemic in Yap, three quarters of the local population are estimated to have been infected [7]. The expanding distribution area of ZIKA makes Zika fever an emerging disease [8], confirmed by the present epidemic affecting French Polynesia since October 2013, and the New Caledonian reported cases since the end of 2013 [1].

The real incidence of Zika fever is unknown, due to clinical manifestations mimicking dengue virus infection, and to lack of simple reliable laboratory diagnostic tests. In endemic areas, epidemiological studies showed a high prevalence of antibodies against ZIKA $[9,10]$. For instance, Yap's epidemic in 2007 resulted in an attack rate of 14.6/1,000 inhabitants and a seroprevalence of $75 \%$ after the epidemic. However, this prevalence is certainly overestimated, due to crossreaction between antibodies directed against ZIKA and other arboviruses such as DENV $[3,11]$.

Like other arboviral diseases, ZIKA is transmitted by arthropods, mainly involving vectors of the Aedes genus, as ZIKA was isolated from numerous species of Aedes mosquitoes in different parts of the world [12-14]. Interestingly, since the first description of Ae. albopictus as a potential vector of ZIKA in 2007 by Wong et al., other reports have suggested that the rapid worldwide expansion of this vector could be responsible for the emergence of new ZIKA infection epidemics, including in urban areas $[15,16]$. Based on epidemiological evidence, Ae. aegypti and Ae. polynesiensis are suspected to be the vectors for the ongoing French Polynesia's epidemic (data not shown). The abundance of competent vectors in the Pacific areas and air travel of viraemic individuals between Pacific island countries and territories are very likely to account for the expansion of ZIKA in this part of the world.

Infection is reported to be symptomatic in $18 \%$ of cases only [7]. When symptomatic, ZIKA infection usually presents as an influenza-like syndrome, often mistaken with other arboviral infections like dengue or chikungunya. The typical form of the disease associates a low-grade fever (between $37.8^{\circ} \mathrm{C}$ and $38.5^{\circ} \mathrm{C}$ ), arthralgia, notably of small joints of hands and feet, with possible swollen joints, myalgia, headache, retroocular headaches, conjunctivitis, and cutaneous maculopapular rash. Digestive troubles (abdominal pain, diarrhoea, constipation), mucous membrane ulcerations (aphthae), and pruritus can be more rarely observed. A post-infection asthenia seems to be frequent $[5,7,17]$.

Confirmed diagnosis is given by RT-PCR, which specifically detects the virus during viraemia [3]. In-house ELISA serological tests can testify the presence of ZIKA $\operatorname{IgM}$ and flaviviruses IgG, whereby specificity is determined by seroneutralisation.

\section{Discussion and conclusion}

During this ongoing Zika fever outbreak in French Polynesia, we report the first case of GBS developing seven days after an influenza-like illness evoking ZIKA infection. Based on IgM/IgG serological results and PNRT which, according to our experience, is reliable and specific enough to differentiate a recent ZIKA infection from cross-reactions due to former infections to DENV, we believe that this is the first case of hospitalisation because of a severe ZIKA infection.

Since the beginning of this epidemic, and as up to 8,200 cases of ZIKA infection have already been reported of a 268,000 total population, the incidence of GBS has been multiplied by 20 in French Polynesia (data not shown), raising the assumption of a potential implication of ZIKA.

Underlying physiopathological mechanisms of Zikarelated GBS is unknown, and could be of immunological origin as described with other infectious agents [18]. There is also no explanation for the emergence of this previously undescribed complication, which could lie in a genetic evolution of the virus to a more pathogenic genotype, or a particular susceptibility in the Polynesian population.

As suggested by DENV and ZIKA serological tests in our patient, the simultaneous epidemics of type 1 and 3 dengue fever may also be a predisposing factor 
for developing GBS during Zika fever, as DENV infection had also been associated with GBS $[19,20]$. Our patient, like part of others who also presented a GBS, harboured serological markers of resolute dengue and recent ZIKA infections. This raises the hypothesis of a sequential arboviral immune stimulation responsible for such unusual clustering of GBS cases during concurrent circulation of ZIKA and two dengue serotypes. The risk of developing GBS would be consequently underlain by a specific sequence of DENV and ZIKA infections.

Therefore in endemic areas, clinician should be aware of the risk of diffuse demyelinating disorder in case of ZIKA infection.

\section{Conflict of interest}

None declared.

\section{Authors' contributions}

EO, LW, FV wrote the manuscript. EO, LW, PL, FG took part in the clinical management of the patient. SL, DM collaborated in molecular biology techniques. ILG collaborated on the virological investigation and on the manuscript writing. All authors participated in the outbreak investigation. All authors read and approved the final manuscript.

\section{References}

1. Kutsuna S, Kato Y, Takasaki T, Moi ML, Kotaki A, Uemura H, et al. Two cases of Zika fever imported from French Polynesia to Japan, December 2013 to January 2014. Euro Surveill. 2014;19(4):pii=20683.

2. Drosten C, Göttig S, Schilling S, Asper M, Panning M, Schmitz $\mathrm{H}$, et al. Rapid detection and quantification of RNA of Ebola and Marburg viruses, Lassa virus, Crimean-Congo hemorrhagic fever virus, Rift Valley fever virus, dengue virus, and yellow fever virus by real-time reverse transcription-PCR. J Clin Microbiol. 2002;40(7):2323-30. http://dx.doi.org/10.1128/JCM.40.7.2323-2330.2002

3. Lanciotti RS, Kosoy OL, Laven JJ, Velez JO, Lambert AJ, Johnson AJ, et al. Genetic and serologic properties of Zika virus associated with an epidemic, Yap State, Micronesia, 2007. Emerg Infect Dis. 2008;14(8):1232-9. http://dx.doi.org/10.3201/eid1408.080287

4. Weinbren MP, Williams MC. Zika virus: further isolations in the Zika area, and some studies on the strains isolated. Trans $\mathrm{R}$ Soc Trop Med Hyg. 1958;52(3):263-8. http://dx.doi.org/10.1016/0035-9203(58)90085-3

5. Simpson DI. Zika Virus Infection in Man. Trans R Soc Trop Med Hyg. 1964:58:335-8.

http://dx.doi.org/10.1016/0035-9203(64)90201-9

6. Olson JG, Ksiazek TG, Suhandiman, Triwibowo. Zika virus, a cause of fever in Central Java, Indonesia. Trans R Soc Trop Med Hyg. 1981;75(3):389-93. http://dx.doi.org/10.1016/0035-9203(81)90100-0

7. Duffy MR, Chen TH, Hancock WT, Powers AM, Kool IL, Lanciotti RS, et al. Zika virus outbreak on Yap Island, Federated States of Micronesia. N England J Med. 2009;360(24):2536-43. http://dx.doi.org/10.1056/NEJMoa0805715

8. Haddow AD, Schuh AJ, Yasuda CY, Kasper MR, Heang V, Huy R, et al. Genetic characterization of Zika virus strains: geographic expansion of the Asian lineage. PLoS Negl Trop Dis. 2012;6(2):e1477.

http://dx.doi.org/10.1371/journal.pntd.0001477

9. Fagbami AH. Zika virus infections in Nigeria: virological and seroepidemiological investigations in Oyo State. J Hyg. 1979;83(2):213-9.

http://dx.doi.org/10.1017/So022172400025997
10. Fokam EB, Levai LD, Guzman H, Amelia PA, Titanji VP, Tesh RB, et al. Silent circulation of arboviruses in Cameroon. East Afr Med J. 2010;87(6):262-8.

11. Faye O, Dupressoir A, Weidmann M, Ndiaye M, Alpha Sall A. One-step RT-PCR for detection of Zika virus. J Clin Virology. 2008;43(1):96-101. http://dx.doi.org/10.1016/j.jcv.2008.05.005

12. Haddow AJ, Williams MC, Woodall JP, Simpson DI, Goma LK. Twelve Isolations of Zika Virus from Aedes (Stegomyia) Africanus (Theobald) Taken in and above a Uganda Forest. Bull World Health Organ. 1964;31:57-69.

13. Adam F, Digoutte JP. Flavivirus, Zika : 606 souches identifiées. Pasteur Institute and Institut de recherche pour le développement. CRORA database internet. c2005. Available from: http://www.pasteur.fr/recherche/banques/CRORA/virus/ v010180.htm

14. Li MI, Wong PS, Ng LC Tan CH. Oral susceptibility of Singapore Aedes (Stegomyia) aegypti (Linnaeus) to Zika virus. PLoS Negl Trop Dis. 2012;6(8):e1792.

15. Grard G, Caron M, Mombo IM, Nkoghe D, Mboui Ondo S, liolle D, et al. Zika Virus in Gabon (Central Africa) - 2007: A New Threat from Aedes albopictus? PLoS Negl Trop Dis. 2014;8(2):e2681. http://dx.doi.org/10.1371/journal.pntd.0002681

16. Wong PS, Li MZ, Chong CS, Ng LC, Tan CH. Aedes (Stegomyia) albopictus (Skuse): a potential vector of Zika virus in Singapore. PLoS Negl Trop Dis. 2013;7(8):e2348. http://dx.doi.org/10.1371/journal.pntd.0002348

17. Heang V, Yasuda CY, Sovann L, Haddow AD, Travassos da Rosa AP, Tesh RB, et al. Zika virus infection, Cambodia, 2010. Emerg Infect Dis. 2012;18(2):349-51. http://dx.doi.org/10.3201/eid1802.111224

18. Hardy TA, Blum S, McCombe PA, Reddel SW. Guillain-barré syndrome: modern theories of etiology. Curr Allergy Asthma Rep. 2011;11(3):197-204. http://dx.doi.org/10.1007/s11882-011-0190-y

19. Carod-Artal FJ, Wichmann O, Farrar J, Gascón J. Neurological complications of dengue virus infection. Lancet Neurol. 2013;12(9):906-19. http://dx.doi.org/10.1016/ S1474-4422(13)70150-9

20. Oehler E, Le Henaff O, Larre P Ghawche F. [Guillain-Barre syndrome following type 4 dengue in Polynesia]. Med Trop (Mars). 2011;71(2):203-4. French. 